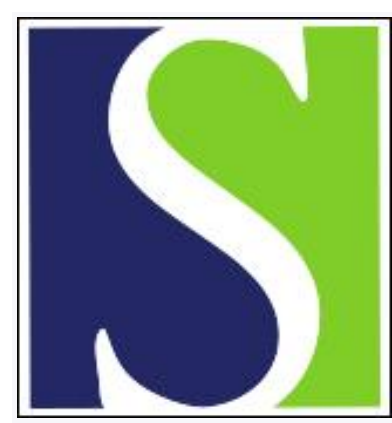

Scand J Work Environ Health 1991;17(4):276-280

https://doi.org/10.5271/sjweh.1702

Issue date: Aug 1991

Histamine and endotoxin contamination of hay and respirable hay dust.

by Siegel PD, Olenchock SA, Sorenson WG, Lewis DM, Bledsoe TA, May J, Pratt DS

Affiliation: National Institute for Occupational Safety and Health, Morgantown, West Virginia 26505.

This article in PubMed: www.ncbi.nlm.nih.gov/pubmed/1925440

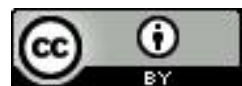




\title{
Histamine and endotoxin contamination of hay and respirable hay dust
}

\author{
by Paul D Siegel, PhD, ${ }^{1}$ Stephen A Olenchock, PhD, ${ }^{1}$ WG Sorenson, PhD, ${ }^{1}$ Daniel M Lewis, PhD, ${ }^{1}$ \\ Toni A Bledsoe, $\mathrm{MS}^{1}$ John J May, MD, ${ }^{2}$ David S Pratt, $M D^{2}$
}

\begin{abstract}
SIEGEL PD, OLENCHOCK SA, SORENSON WG, LEWIS DM, BLEDSOE TA, MAY JJ, PRATT DS. Histamine and endotoxin contamination of hay and respirable hay dust. Scand $J$ Work Environ Health 1991;17:276-80. Three distinct samples collected from a barn in which an outbreak of respiratory problems occurred were examined for possible etiologic agents. No causal relationship could be established from the results of this study; however histamine concentrations as high as $0.5 \mathrm{ng} / \mathrm{mg}$ for bulk hay (in the absence of measurable creatinine levels) along with 6138.3 endotoxin units $/ \mathrm{mg}$ of hay were present in the samples. Both endotoxin and histamine could be recovered from respirable hay dust. The authenticity of the histamine found in the hay was evaluated with high-performance liquid chromatography and radioimmunoassay. Histamine release caused by hay extracts was evaluated with the use of leukocytes from the farmer and a referent. Histamine is known to modulate the immune system, but the role of occupational or environmental exposure to histamine in respiratory disease is unknown.
\end{abstract}

Key terms: hay, histamine, respiratory disease.

Agricultural dust that may cause adverse respiratory effects has been an ongoing area of concern and study in our laboratory. A recent study of endotoxin air concentrations associated with bedding choppers demonstrated levels as high as 27096 endotoxin units $/ \mathrm{m}^{3}$ (1). The bedding chopper is a mechanical device which cuts hay into short lengths and blows the hay into cattle stalls to be used as bedding by the dairy cows. This operation creates a considerable dust cloud containing high levels of endotoxin. Endotoxin, a pyrogen, is also commonly found in high levels in cotton dust associated with respiratory disease (2).

Prior to the recognition of the possible role of endotoxin in occupational respiratory disease, directacting bronchoactive agents were identified in cotton dust extracts (3-6). Haworth \& MacDonald (5) separated, purified, and chemically identified the presence of histamine from cotton dust. More recently, Russell \& Rohrbach (6) reported the presence of two directacting bronchoconstrictive agents in cotton bract extracts. They concluded that one of the compounds was not 5-hydroxytryptamine (5-HT), but acted at the 5-HT receptor. The other agent was identified as histamine. The relationship between the presence of bronchoactive factors and pyrogens in other agricultural dust or the development of respiratory disease has not been investigated.

1 National Institute for Occupational Safety and Health Morgantown, West Virginia, United States.

2 New York Center for Agricultural Medicine and Health Cooperstown, New York, United States.

Reprint requests to: Dr PD Siegel, Biochemistry Section, NIOSH, 944 Chestnut Ridge Road, Morgantown, WV 26505, USA.
The present study examined three hay samples from a barn in which the dairy cows displayed asthmalike symptoms. The herd was established on the farm in May 1989 and consisted of 50 milk cows (Jerseys and Holsteins). The first cow became sick, coughing and wheezing with shortness of breath in August. Chopping of an old hay that had been left in the barn for bedding and the use of a newly purchased dusty hay as feed was also begun in August. By mid-September approximately $50 \%$ of the herd displayed similar respiratory symptoms, most notably after being fed. The number of cows displaying respiratory symptoms increased through November, when the chopping of hay for bedding was stopped and the hays were removed. By mid-December some resolution of symptoms was noticed. The parallel between the use of the hays and onset and resolution of bovine respiratory symptoms implicated the hay as the probable source of the problems. The dairy farmer who operated the bedding chopper had no respiratory symptoms during the day but complained of congestion at night. Hay extracts were tested for endotoxin content, potential to cause basophil degranulation in the farmer and a matched unexposed referent, and histamine concentration. We also acoustically generated a respirable dust cloud from the hay samples in the laboratory to assess whether endotoxin and histamine could be introduced into the air from these chopped hay samples.

\section{Materials and methods}

\section{Collection and extraction of the hay}

Three different hay samples were recovered from the barn in question. The first sample (hay 1) consisted 
of hay and hay chaff stored in the ceiling. It was approximately five years old. This hay had been exposed to considerable moisture and was greatly decayed. The second sample (hay 2) was newly purchased from a local source. It had been rejected by a horse farmer due to its dusty nature. The third sample (hay 3) had been stored in the barn and was of undetermined age. It had also become wet during storage. Hay 3 was being used for bedding.

Representative samples of each hay ( $40 \mathrm{~g}$ ) were extracted into 11 of nonpyrogenic sterile water (Travenol Laboratories, Deerfield, Illinois, United States). The extracts were centrifuged at $1000 \mathrm{~g}$ for $10 \mathrm{~min}$, and the supernatant fluids were recovered, aliquoted, and stored at $-80^{\circ} \mathrm{C}$ until use.

\section{Analysis of histamine}

Histamine extraction, o-phthalaldehyde (OPT) condensation, and high-performance liquid chromatographic (HPLC) analysis were performed as previously described (7). The authenticity of histamine was confirmed with a commercially available radioimmunoassay (RIA) (Biomerica, Newport Beach, California, United States). The procedure of Biomerica catalog number 1051 was followed for the identification of the histamine. Histamine standards were run in parallel to all the samples.

\section{Endotoxin analysis}

The supernatant fluids were assayed in duplicate for the presence of gram-negative bacterial endotoxins with the chromogenic modification of the Limulus amebocyte lysate test (QCL-1000; Whittaker Bioproducts, Walkersville, Maryland, United States) as currently recommended by the Workgroup on Agents in Organic Dusts (8). The results were reported in terms of endotoxin units (EU) per milligram of dust.

\section{Creatinine analysis}

Creatinine was measured by the clinical chemistry single-slide method (Eastman Kodak Co, Rochester, New York, United States). The assay was performed on an automated clinical chemistry instrument with a $0.1 \mathrm{mg} / \mathrm{dl}$ limit of detection.

\section{Hay dust generation and collection}

The hay samples were chopped, sieved through a 20-mesh stainless steel screen and added to a Pitt 3 dust generator (University of Pittsburgh, Pittsburgh, Pennsylvania, United States). Filtered air was introduced into the generator at $2 \mathrm{l} / \mathrm{min}$ and mixed with filtered room air prior to being introduced into a 20-1 glass settling chamber. The exhaust airflow was maintained at $7.4 \mathrm{l} / \mathrm{min}$. Respirable dust was collected at $1.7 \mathrm{l} / \mathrm{min}$ through a 10-mm cyclone (Mine Safety Appliances Co, Pittsburgh, Pennsylvania, United States) onto a preweighed 37-mm, 0.45- $\mu \mathrm{m}$ HA filter (Millipore, Bedford, Massachusetts, United States). The total dust concentration was determined from air collected at $4.25 \mathrm{l} / \mathrm{min}$ through an in-line $37-\mathrm{mm}, 0.45-\mu \mathrm{m} \mathrm{HA}$ filter. The filters were reweighed and extracted with $2 \mathrm{ml}$ of sterile water. The extract was centrifuged at $1000 \mathrm{~g}$ for $10 \mathrm{~min}$, and the supernatant fluid was recovered for endotoxin and histamine determinations.

\section{Basophil histamine release assay}

An enriched basophil preparation was obtained by isoosmotic discontinuous percoll gradients $(\mathrm{d}=1.078$ and 1.098) from blood samples treated with ethylenediamine tetraacetate. A concentrated piperazine-N-N'bis(2-ethanesulfonic acid) (PIPES) buffer (Sigma Chemical Co, St Louis, Missouri, United States) was added to each hay extract to obtain a final buffer concentration containing $110 \mathrm{mM}$ sodium chloride, $5 \mathrm{mM}$ potassium chloride, $25 \mathrm{mM}$ PIPES, $1 \mathrm{mM}$ calcium chloride, $1 \mathrm{mM}$ magnesium sulfate, and $0.1 \%$ bovine serum albumin. The final buffered hay extract was $90 \%$ [volume/volume $(\mathrm{v} / \mathrm{v})$ ] of the original unbuffered extract and is denoted as $1 \times$ concentration. Approximately $4 \times 10^{4}$ basophils were used per tube. The cells were incubated for $30 \mathrm{~min}$ at $37^{\circ} \mathrm{C}$. Supernatant fluid was recovered, protein-precipitated with $2 \%$ perchloric acid (final concentration), and stored at $4^{\circ} \mathrm{C}$ until extracted for HPLC fluorometric analysis. Cell pellets were resuspended in PIPES buffer, lysed, protein-precipitated, and stored in a similar manner. Positive release was considered to be $>10 \%$. The percentage of histamine release (HR) was determined by the following equation:

$$
\% \mathrm{HR}=(\mathrm{SFH}-\mathrm{HEH}) /(\mathrm{SFH}+\mathrm{CPH}-\mathrm{HEH})
$$

where $\mathrm{SFH}=$ supernatant fluid histamine, $\mathrm{HEH}=$ hay extract, histamine, and $\mathrm{CPH}=$ cell pellet histamine.

\section{Radioallerosorbent test}

The radioallerosorbent test (RAST) was performed as described by Adolphson et al (9). Hay extracts were lyophilized and then reconstituted in the bicarbonate

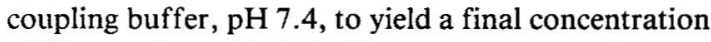
of $20 \mathrm{mg}$ of protein $/ \mathrm{ml}$. These concentrated hay extracts were bound to cyanobromide-activated 4B sepharose beads. Suspensions of the bead $(50,100$, and $200 \mu \mathrm{l})$ were incubated with 50,100 , and $200 \mu \mathrm{l}$ of farmer or reference sera for $3 \mathrm{~h}$ at $25^{\circ} \mathrm{C}$. The beads were washed and ${ }^{125}$ I-labeled antihuman immunoglobulin E (anti-IgE) (Pharmacia Diagnostics, Piscataway, New Jersey, United States). Bound ${ }^{125}$ I-anti-IgE was quantitated with a Micromedic 2/200 gamma counter (Horsham, Pennsylvania, United States). 


\section{Results}

Endotoxin was measured in the bulk hay extracts and from dust samples generated from hay (table 1). Bulk hay endotoxin ranged from 93 to $6138.3 \mathrm{EU} / \mathrm{mg}$ of hay. A dust cloud was generated from each hay sample with the Pitt 3 dust generator, and samples of total and respirable dust were collected. There was little difference between the respirable and total dust concentrations (table 2), and therefore almost the entire dust cloud was probably of respirable size $(<10 \mu \mathrm{m})$. The endotoxin units per microgram of hay dust in samples hay 1 and hay 3 were greater than the corresponding content of bulk hay, while sample hay 2 demonstrated the reverse relationship.

The histamine content of the same bulk hay and hay dust extracts was also analyzed (table 3 ). Histamine could not be detected in the bulk or dust samples of hay 1 . Hay 2 and 3 contained 0.5 and 0.175 ng of hista$\mathrm{mine} / \mathrm{mg}$ of bulk hay, respectively. The histamine concentration in the dust generated from hay 2 and 3 was considerably higher than the bulk concentrations and contained up to $7 \mathrm{ng}$ of histamine/ $\mathrm{mg}$ of hay dust. This finding suggested that the histamine was not directly from the hay, but a contaminant of it. The histamine content of the extracts was quantitated by organic extraction, followed by condensation to OPT and measurement by HPLC fluorometry. Figure 1 is a chromatograph of the hay 2 extract. Two fluorescent peaks

Table 1. Endotoxin concentration of hay samples collected from the barn and aerosolized hay dust.

\begin{tabular}{|c|c|c|c|}
\hline \multirow[b]{2}{*}{ Sample } & \multicolumn{3}{|c|}{ Endotoxin (EU/mg of hay or hay dust) } \\
\hline & Bulk hay & $\begin{array}{c}\text { Total } \\
\text { airborne dust }\end{array}$ & $\begin{array}{c}\text { Respirable } \\
\text { airborne dust }\end{array}$ \\
\hline $\begin{array}{l}\text { Hay } 1 \\
\text { Hay } 2 \\
\text { Hay } 3\end{array}$ & $\begin{array}{r}93.0 \\
6138.3 \\
783.7\end{array}$ & $\begin{array}{r}603.9 \\
1284.6 \\
1106.9\end{array}$ & $\begin{array}{c}474.6 \\
\cdots \\
1473.6\end{array}$ \\
\hline
\end{tabular}

Table 2. Chamber hay dust concentrations aerosolized by the Pitt 3 generator.

\begin{tabular}{lcc}
\hline Sample & $\begin{array}{c}\text { Total dust } \\
\left(\mathrm{mg} / \mathrm{m}^{3}\right)\end{array}$ & $\begin{array}{c}\text { Respirable dust } \\
\left(\mathrm{mg} / \mathrm{m}^{3}\right)\end{array}$ \\
\hline Hay 1 & 13.0 & 10.0 \\
Hay 2 & 1.3 & $\cdots$ \\
Hay 3 & 6.2 & 5.7 \\
\hline
\end{tabular}

Table 3. Histamine concentration of hay samples coilected from the barn and aerosolized hay dust. (ND = not detectable)

\begin{tabular}{lccc}
\hline \multirow{2}{*}{ Sample } & \multicolumn{3}{c}{ Histamine (ng/mg of hay or hay dust) } \\
\cline { 2 - 4 } & Bulk hay & $\begin{array}{c}\text { Total } \\
\text { airborne dust }\end{array}$ & $\begin{array}{c}\text { Respirable } \\
\text { airborne dust }\end{array}$ \\
\hline Hay 1 & ND & ND & ND \\
Hay 2 & 0.500 & 7.0 & $\overline{-}$ \\
Hay 3 & 0.175 & 2.8 & 3.48 \\
\hline
\end{tabular}

were eluted from the column, one of which eluded at the same time as the OPT histamine. Histamine was added to hay 2 and 3 extracts, extracted, derivatized, and chromatographed. The authentic histamine and the hay histamine-like peak could not be separated. The authenticity of the histamine from the hay extracts was further confirmed with the use of a double antibody ${ }^{3} \mathrm{H}$-labeled RIA. The RIA indicated the presence of histamine in hays 2 and 3, but not in hay 1 . The source of the histamine is unknown; however creatinine could not be detected in any of the hay samples (limit of detection $=0.1 \mathrm{mg} / \mathrm{dl}$ ).

Basophils from the dairy farmer to whom the hay belonged and a nonsensitized matched referent were challenged with each of the hay extracts at two concentrations (table 4). Anti-IgE was used as a positive control of IgE-mediated basophil degranulation. The farmer's basophils released $11.9 \%$ of their histamine in response to a $1 / 1000$ titer of anti-IgE. Hay extracts 1 and 3 produced histamine release greater than that 
produced by anti-IgE at $1 \times$ concentration and hay 3 at the $0.1 \times$ concentration. The matched nonsensitized referents's basophils released $41.3 \%$ of their histamine to anti-IgE, but failed to release $>10 \%$ of their histamine to any of the hay extracts.

Evaluation of specific IgE directed toward hay antigens with RAST of both the farmer's and the referent's sera was performed. Specific IgE was not detected in either sera with this method.

\section{Discussion}

Organic dust may be generated from many farming processes. One such dusty farm operation, the chopping of bedding for animals, has been studied previously (1). Farm workers involved in bedding chopper operations were shown to have personal exposures of up to $69.4 \mathrm{mg} / \mathrm{m}^{3}$ of dust containing $27096.2 \mathrm{EU} / \mathrm{m}^{3}$ of air. Endotoxin was associated with every size fraction of dust, and the size associated with the greatest endotoxin activity varied between the hay samples. The hay sample endotoxin levels examined in the present study are consistent with that previously reported (1). An analysis of the bulk hay extracts demonstrated that the total endotoxin content can vary greatly from one hay sample to the next.

Hay dust from hays 1,2, and 3 was generated with a Pitt 3 dust generator. Although this method of dust generation does not simulate that of the bedding chopper operation, it does generate samples containing components associated with a respirable dust size. The endotoxin activity in the aerosolized dust from hay 1 and hay 3 was greater than in the bulk samples, while in hay 2 it was less. The endotoxin in hay 2 may have been associated with a larger particulate size and thus not present in our dust cloud. Such variation in the particle size of hay dust associated with endotoxin has been reported previously (1).

The presence of histamine in the two hay samples with the highest endotoxin contamination is of great interest because both histamine (4) and endotoxin $(1,2)$ have been identified in cotton dust extracts at similar concentrations. The endotoxin level in cotton dust has been suggested to be important in the manifestation of acute respiratory disease (2). The bulk hay extracts with high levels of endotoxin also contained the highest histamine, while no histamine was detected in hay 1, which had the lowest endotoxin activity of the three samples. None of the hay samples had detectable levels of creatinine which would suggest that the histamine was not from an animal source. Bacteria are a possible source of histamine, and, in particular, gram-negative bacteria have been shown to produce histamine (10).

The activity of histamine in laboratory bioassays used to assess extracts of agricultural samples is of concern. Extracts containing histamine may affect the measurement of immunologic parameters such as
Table 4. Basophil histamine release by hay extracts. ${ }^{a}(\mathrm{lg}=\mathrm{im}-$ munoglobulin)

\begin{tabular}{lcc}
\hline & Farmer & $\begin{array}{c}\text { Unexposed } \\
\text { referent }\end{array}$ \\
\cline { 2 - 3 } Basal release & 2.6 & $<1.0$ \\
Anti-IgE (1/1000) & $11.9^{\mathrm{b}}$ & $41.3^{\mathrm{b}}$ \\
Hay 1 & $12.5^{\mathrm{b}}$ & 7.1 \\
0.1 hay 1 & $<1.0$ & $<1.0$ \\
Hay 2 & 5.0 & 5.4 \\
0.1 hay 2 & 5.0 & 1.0 \\
Hay 3 & $25.8^{\mathrm{b}}$ & 3.8 \\
0.1 hay 3 & $13.4^{\mathrm{b}}$ & 1.4 \\
\hline
\end{tabular}

a All values are represented as the percentage of release of total basophil histamine corrected for background histamine.

b Greater than $10 \%$ or anti-IgE positive control release was considered positive.

basophil degranulation. $\mathrm{H}_{2}$ receptor activation can inhibit basophil degranulation (11) and possibly cause a false negative finding in allergy testing from crude extracts. Dialysis of extracts could remove the histamine while preserving many of the allergens.

The etiology of the observed bovine respiratory condition may not be fully attributable to histamine or endotoxin. These hays also contained appreciable levels of fungi and bacteria, which we are now in the process of characterizing. The involvement of an infectious agent in the underlying etiology cannot be ruled out. The high percentage of cows ( $>80 \%$ of the herd) displaying respiratory symptoms tends to imply that a toxic exposure or infection was involved. Likewise, the basophil degranulation induced in the farmer by the hay extract does not necessarily denote a relationship with clinical symptomology.

The importance of occupational or environmental inhalation exposure to histamine is not known. Histamine has been shown to modulate the immune system through both $\mathrm{H}_{1}$ and $\mathrm{H}_{2}$ receptors at levels as low as $10^{-9} \mathrm{M}(12)$. This study demonstrated that histamine was associated with the respirable fraction of hay dust. The pathological importance of such an observation is unknown, but the biological activity of inhaled endotoxin may be altered by the concomitant exposure to histamine. Recent evidence suggests that the coexistence of histamine with endotoxin may be important in that endotoxin may increase the reactivity of the coronary vascular system to histamine in guinea pigs (13). Occupational exposure to histamine-containing organic dust corld, therefore, affect the human reaction to the response of heterogenous dusts. A greater understanding of the effect of environmental or occupational exposure to histamine on the respiratory tract and immune systems and its relationship to pyrogens such as endotoxin is needed.

\section{Acknowledgments}

This work was done while the senior author held a National Research Council research associateship. 
Mention of company names or products does not constitute endorsement by the National Institute for Occupational Safety and Health.

\section{References}

1. Olenchock SA, May JJ, Pratt DS, Piacitelli LA, Parker JE. Presence of endotoxins in different agricultural environments. Am J Ind Med 1990;18:279-84.

2. Castellan RM, Olenchock SA, Kinsley KB, Hankinson $\mathrm{JL}$. Inhaled endotoxin and decreased spirometric values: an exposure-response relation for cotton dust. N Engl J Med 1987;317:605-10.

3. Maitland HB; Heap H, MacDonald, AD. Report to the departmental committee on dust in card rooms in the cotton industry: appendix VI. London: Her Majesty's Stationery Office, 1932;87-91.

4. Prausnitz C. Medical Research Council report: investigations on respiratory dust diseases in operatives in the cotton industry. London: His Majesty's Stationery Office. $1936 ; 1-72$.

5. Haworth E, MacDonald AD. On histamine in cotton dust, and in the blood of cotton workers. J Hyg 1937; $37: 234-42$.

6. Russell JA, Rohrbach MS. Partial isolation of bronchoactive factors in cotton bracts. In: Jacobs RR, Wakelynand PJ, ed. Proceedings of the 10th cotton dust research conference. Memphis, TN: National Cotton Council, 1986:140-1.

7. Siegel PD, Lewis DM, Olenchock, SA. High performance liquid chromatographic method for the evaluation of possible interferences in basophil-histamine release measurements. Anal Biochem 1990;188:416-21.

8. Popendorf W. Reports on agents. Am J Ind Med 1986; 10:251-9.

9. Adolphson CR, Gleich GJ, Yunginger JW. Standardization of allergens. In: Rose NR, Friedman H, Fahey $\mathrm{JL}$, ed. Manual of clinical laboratory immunology. Washington, DC: American Society for Microbiology, 1986:652-9.

10. Devalia SL, Grady D, Harmanyeri Y, Tabagchali S, Davies RS. Histamine synthesis by respiratory tract micro-organisms: possible role in pathogenicity. J Clin Pathol 1989;42:516-22.

11. Bourne HR, Melmon KL, Lichtenstein LM. Histamine augments leucocyte cyclic AMP and blocks antigenic histamine release. Science 1971;173:743-74.

12. Beer DJ, Rocklin RE. Histamine-induced suppressorcell activity. J Allergy Clin Immunol 1984;73(4):439— 52.

13. van Heuven-Nolsen D, Have T, Nijkamp FP. Increased reactivity to histamine in the coronary vascular system of the guinea-pig after endotoxin. Agents Action 1989; $27(1 / 2) ; 158-9$.

Received for publication: 14 May 1990 